\title{
Wax deposition model of heavy oil in pipeline transportation
}

\author{
Shiming Chen ${ }^{1}$, Yan Chen ${ }^{1, *}$, Junze Jiang ${ }^{1}$, Bowen Lou ${ }^{1}$, and Jimiao Duan ${ }^{1}$ \\ ${ }^{1}$ Department of Petroleum, Army Logistics Academy, Chongqing, China
}

\begin{abstract}
During the transportation process of heavy oil, wax deposition is prone to occur for the low temperature outside the tube and strong heat exchange, which will adversely affect the pipeline transportation of heavy oil. Based on the experimental data of the indoor deposition loop, this paper considered the impact of strong environmental heat transfer and oil flow shear on wax deposition and established a kinetic model of wax deposition for pipeline transportation of heavy oil. Numerical simulation was performed on the flow field and temperature field during the wax deposition process to obtain the model parameters. Through analyzing the deposition rate computed by the model, this paper reveals the effect of oil flow velocity, oil temperature and wall temperature difference on wax deposition.
\end{abstract}

Keywords: Pipe transportation; Wax deposition; Model; Numerical simulation.

\section{Introduction}

In the process of heating and transporting heavy oil, due to the strong heat exchange effect of the environment, the temperature of the heavy oil in the pipeline will gradually decrease, and the heavy oil dissolved in the vicinity of the pipe wall, which will directly affect the pressure and temperature distribution along the pipeline, and even causes serious accidents, such as pipeline blockage and condensation ${ }^{[1]}$.

Since the end of the 20th century, scholars at home and abroad have carried out a lot of research on wax deposition problems and proposed many wax deposition kinetic models, including Burger model ${ }^{[2]}$, Hsu model ${ }^{[3]}$, Hamouda model ${ }^{[4]}$, Singh model ${ }^{[5]}$. On the basis of the Singh model, Hernande $z^{[6]}$ considered the flow resistance of oil flow shear and wax deposition, and proposed a new wax deposition rate model and a calculation model for the wax content in the sediment, however, the model did not consider the effect of deposition aging on wax deposition. Mehrotra ${ }^{[7]}$ used the shear-induced deformation method to incorporate the effects of deposition aging and established a wax deposition calculation model for unsteady heat transfer, but this model is limited to single-phase heat flow and two-phase heat flow. Ai Yunchao ${ }^{[8]}$ obtained the wax deposition rate expression by defining the wax deposition potential. The model only considers the flow to determine the structural state of the deposit layer, but does not consider the influence on the mass transfer process of wax deposition, which does not conform to the actual situation of pipe flow.

\footnotetext{
* Corresponding author: yansohucom@sohu.com
} 
Through analysis of research status, it is found that the wax deposition model proposed by the predecessors lacks consideration of the influence of low temperature and strong heat exchange environment on wax deposition. Therefore, the paper established a dynamic model of wax deposition in oil pipelines by analyzing the shearing effect of oil flow and the "aging" effect of wax deposits, which is of great significance to establish the wax deposition model of pipeline transportation of heavy oil for improving the efficiency and safety of heavy oil transportation.

\section{Numerical simulation of heavy oil wax deposition process in pipeline transportation}

\subsection{Mathematical model of wax deposition in pipe}

In the process of pipeline transportation of heavy oil, the main mechanism that causes wax deposition is the influence of molecular diffusion, oil flow shearing effect and "aging" effect $^{[9]}$. When wax molecules are deposited on the wax deposition layer by molecular diffusion, they will also be sheared by the oil flow in the pipe. After the wax deposition layer is formed, the wax content in the deposition layer will gradually "aging" under the action of back diffusion, leading to the increase of the thermal conductivity of the wax deposition layer and the hardness of the deposition layer, and reducing the diffusion coefficient of wax molecules in the deposition layer(Fig. 1).

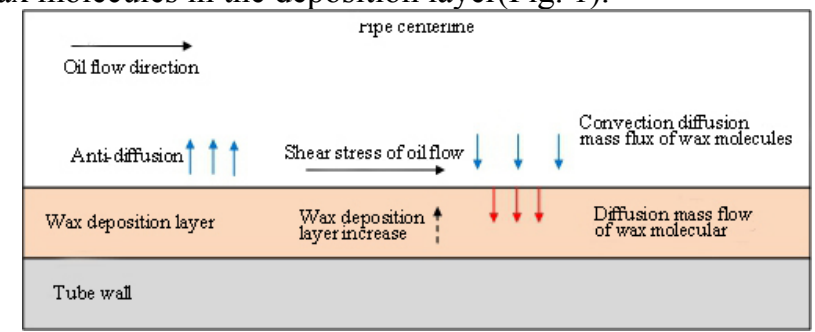

Fig. 1. Schematic diagram of the process of depositing heavy oil wax.

\subsubsection{Effective amount of wax precipitation}

The temperature gradient is the driving force for the radial movement of the wax crystals, so this determines that the wax crystals have a chance to deposit in the thermal boundary layer. Therefore, before calculating the effective amount of wax precipitation, it is necessary to determine the quality of all heavy oil flowing through the thermal boundary layer and the amount of wax precipitated due to temperature drop during the operation time of the tube.

The mass flow calculation formula in the thermal boundary layer region is:

$$
G_{\delta}=2 \pi \rho \int_{R-\delta}^{R} \frac{\Delta P}{4 \mu \mathrm{l}}\left(R^{2}-r^{2}\right) r d r
$$

Where $G_{\delta}$ is the mass flow through the thermal boundary layer, $\mathrm{kg} / \mathrm{s} ; \rho$ is the oil density, $\mathrm{kg} / \mathrm{s}^{3} ; \delta$ is the thickness of the thermal boundary layer, $\mathrm{m} ; u$ is the flow velocity somewhere in the effective section of the pipe, $\mathrm{m} / \mathrm{s} ; \Delta P$ is the pressure difference between any two sections of the pipeline, $\mathrm{Pa} ; \mu$ is the oil viscosity, $\mathrm{Pa} \cdot \mathrm{s} ; l$ is the axial distance of any section of the pipeline, $\mathrm{m} ; R$ is the effective radius of the pipeline, $\mathrm{m} ; r$ is the radius of a certain point on the effective section of the pipeline, $\mathrm{m}$. 
When the pipeline transportation time is $t$, the effective wax precipitation amount $A_{p}$ can be expressed as:

$$
A_{p}=G_{\delta} \mathrm{t} C
$$

Where $C$ represents the quality of wax crystals precipitated per unit mass of crude oil at different temperatures, which can be found based on experimental data.

\subsubsection{The effect of oil flow shear}

At present, the influence of oil flow shear on wax deposition is generally demonstrated by loop experiments, and an oil flow shear model is established ${ }^{[10]}$. The oil flow shear process is shown in Fig. 2.

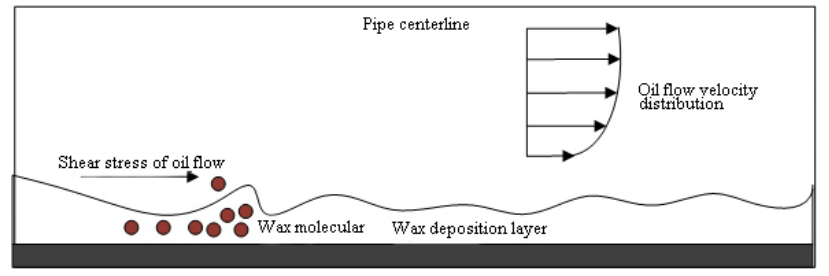

Fig. 2. Schematic diagram of shearing process of pipe heavy oil.

Edmonds et $\mathrm{al}^{[11]}$. established a calculation model for the shear rate of oil flow based on the actual measurement of the experimental loop:

$$
\gamma=\frac{K f \rho \mu \delta}{2 F_{w}^{2.3}}
$$

Where the value of $K$ is $6.6 \times 10^{-4} ; \gamma$ is the shear rate of the oil flow, $\mathrm{s}^{-1} ; f$ is the Fanning friction coefficient, which can be calculated by the Blasius empirical formula ${ }^{[12]} ; F_{w}$ is the mass fraction of solid wax in the deposition layer, $\%$.

\subsubsection{Wax deposition rate}

Among the factors that affect the wax deposition rate, these play a leading role, including the oil viscosity, the solubility coefficient of wax crystals at the pipe wall, the shear stress at the pipe wall, and the temperature gradient at the pipe wall. The deposition rate calculation formula based on the multiple linear regression method is :

$$
\phi=0.0204 \mu^{1.03} \tau^{-1.036}\left(\frac{d T}{d r}\right)^{-0.157}\left(\frac{d C}{d T}\right)^{-0.576}
$$

Where $\tau_{\mathrm{w}}$ is the shear stress at the pipe wall, $\mathrm{Pa} ; \mathrm{dC} / \mathrm{dT}$ is the solubility coefficient of wax crystal at the pipe wall, $10-3 /{ }^{\circ} \mathrm{C} ; \mathrm{dT} / \mathrm{dr}$ is the temperature gradient at the pipe wall, ${ }^{\circ} \mathrm{C}$ $/ \mathrm{mm}$.

Then, under different experimental conditions, the calculation formula of the wax deposition rate of heavy oil in the indoor loop is:

$$
W=\frac{\phi A_{\mathrm{p}}}{\pi d l}
$$

Where $W$ is the wax deposition rate, $\mathrm{g} /\left(\mathrm{m}^{2} \cdot \mathrm{h}\right) ; d$ is the inner diameter of the test section of the experimental loop, $\mathrm{m}$. 


\subsection{Parameters of wax deposition model}

Numerical simulations were carried out on the flow field and temperature field of the test section of the experimental loop during the deposition process to calculate the parameters required for the solution of the heavy oil wax deposition model of pipeline transportation.

\subsubsection{Numerical simulation}

The geometric model(Fig. 3) of the numerical simulation in this paper takes the test section of the wax deposition loop experiment of China University of Petroleum ${ }^{[10]}$ as the prototype. The inner tube transported the heavy oil, the medium transported by outer tube is cooling water. The flow of the inner and outer tubes are in opposite directions, and heat exchange is performed through the inner tube wall.

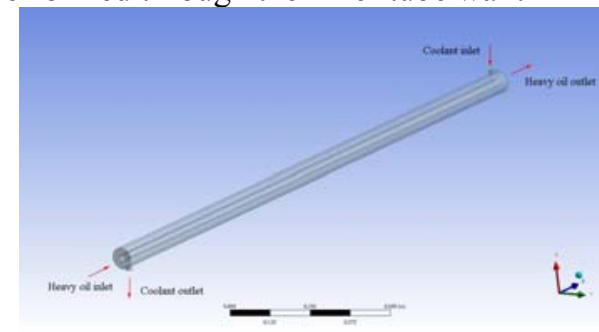

Fig. 3. Wax deposition loop test section geometry model.

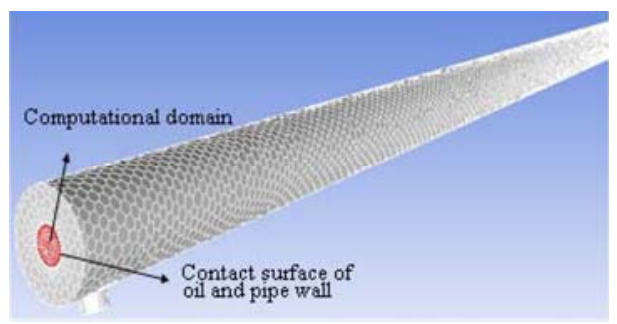

Fig. 4. Mesh of computational domain.

In the entire computational domain(Fig. 4), the fluid control area is a cylinder of $\pi \times 12.52 \mathrm{~mm} \times 2000 \mathrm{~mm}$ (red area). Near the wall of the tubing the grid has been encrypted. The polyhedral mesh is utilized in the solution for its advantages of more accuracy and efficiency. The final number of grid cells in the entire model is 148316.

The flow fields of the two fluids adopted the boundary conditions of velocity inlet and pressure outlet. Double-precision calculation was selected, and the SIMPLE algorithm was applied to solve pressure-velocity coupling. In the boundary condition setting, the sub-relaxation factors of pressure, density, momentum, energy, etc. were all set to default values, and the velocity and energy residuals were respectively $1 \times 10^{-3}$ and $1 \times 10^{-6}$ for convergence. The heat transfer model of the test section adopted the enthalpy model (thermal energy), only the convection heat transfer between the liquid and the pipe wall and the heat conduction of the tubing wall were calculated. Changes on viscosity and temperature of the heavy oil were realized by the software user-defined function. The convective heat transfer between the heavy oil and the inner wall of the oil pipe and the coolant and the outer wall of the oil pipe was selected when the boundary conditions are defined, and the wall attribute was set to steel.

\subsubsection{Parameters calculation}

Table 1. Simulation results of heavy oil under fixed conditions.

\begin{tabular}{ccccc}
\hline $\begin{array}{c}\text { Average temperature } \\
\text { gradient } \\
\left({ }^{\circ} \mathrm{C} / \mathrm{mm}\right)\end{array}$ & $\begin{array}{c}\text { Shear } \\
\text { stress } \\
(\mathrm{Pa})\end{array}$ & $\begin{array}{c}\text { Average thickness of } \\
\text { thermal boundary } \\
\text { layer }(\mathrm{mm})\end{array}$ & $\begin{array}{c}\text { Kinetic } \\
\text { viscosity } \\
(\mathrm{Pa} \cdot \mathrm{s})\end{array}$ & $\begin{array}{c}\text { Coefficient of wax } \\
\text { crystal solubility } \\
(\%)\end{array}$ \\
\hline 3.305 & 13.04 & 4.486 & 0.14449 & 4.377 \\
\hline
\end{tabular}

Table.1 shows the simulation results of the wax deposition loop test section of heavy oil when the oil temperature is $40{ }^{\circ} \mathrm{C}$, the flow rate is $0.5 \mathrm{~m} / \mathrm{s}$, the coolant is $20{ }^{\circ} \mathrm{C}$, and the 
flow rate is $0.5 \mathrm{~m} / \mathrm{s}$. Substituting the data in the table into the universal wax deposition model, the calculated wax deposition rate is $62.14 \mathrm{~g} /\left(\mathrm{m}^{2} \cdot \mathrm{h}\right)$.

\section{Numerical simulation result and analysis}

\subsection{Model validation}

In order to verify the feasibility of the pipeline fuel oil wax deposition model proposed in this paper, the wax deposition rate obtained by numerical simulation was compared with the wax deposition rate obtained from the loop experiment of China University of Petroleum $^{[6]}$, as shown in Table.2.

Table 2. Comparison of wax deposition rate simulation results with experimental results.

\begin{tabular}{ccccc}
\hline $\begin{array}{c}\text { Oil } \\
\text { temperature } \\
\left({ }^{\circ} \mathrm{C}\right)\end{array}$ & $\begin{array}{c}\text { Coolant } \\
\text { temperature }\left({ }^{\circ} \mathrm{C}\right)\end{array}$ & $\begin{array}{c}\text { Wax deposition rate } \\
\text { of numerical } \\
\text { simulation }\left(\mathrm{g} /\left(\mathrm{m}^{2} \cdot \mathrm{h}\right)\right)\end{array}$ & $\begin{array}{c}\text { Wax deposition rate } \\
\text { of loop experiment } \\
\left(\mathrm{g} /\left(\mathrm{m}^{2} \cdot \mathrm{h}\right)\right)\end{array}$ & $\begin{array}{c}\text { Relative } \\
\text { error } \\
(\%)\end{array}$ \\
\hline 40 & 35 & 24.55 & 23.42 & 4.82 \\
40 & 30 & 44.43 & 43.31 & 2.57 \\
40 & 25 & 56.36 & 55.34 & 1.84 \\
40 & 20 & 62.14 & 61.08 & 1.74 \\
35 & 20 & 58.68 & 57.36 & 2.3 \\
30 & 20 & 53.87 & 55.96 & 3.73 \\
25 & 20 & 34.52 & 31.93 & 8.11 \\
\hline
\end{tabular}

The maximum error is $8.11 \%$ when the oil temperature and the coolant temperature is $25^{\circ} \mathrm{C}, 20^{\circ} \mathrm{C}$ respectively, and the minimum error is $1.74 \%$ when the oil temperature and the coolant temperature is $40^{\circ} \mathrm{C}, 20^{\circ} \mathrm{C}$ respectively, which shows that the wax deposition model of heavy oil in pipeline transportation established in this paper is reasonable and effective.

\subsection{Conclusion analysis}

\subsubsection{Influence of oil flow speed}

As shown in Fig. 5, the increase of the oil flow velocity will cause the decrease of the deposition rate when the oil temperature and the coolant temperature are constant. This is because the increase in the flow velocity in the pipe causes the pipe wall to shear at the same oil temperature and coolant temperature. When the stress increases, the scouring effect of the oil flow at the pipe wall is not conducive to the occurrence of wax deposition in the pipe. At this time, the temperature gradient, wax crystal solubility, viscosity and other factors close to the pipe wall are basically the same, and the shearing effect is obvious, so the wax deposition rate decreases.

\subsubsection{Influence of oil temperature}

As shown in Fig. 6, the wax deposition rate increases as the oil temperature rises when the oil flow rate and the coolant temperature remain unchanged. The oil temperature rising will cause the oil wall temperature difference to become larger and form a larger temperature gradient, the diffusion ability of wax molecules will increase, and the wax deposition rate will increase, and the temperature difference range will become larger. As the wax precipitation interval becomes longer, more wax can be precipitated per unit time, which 
will also cause the wax deposition rate to increase. When the oil temperature is small, as the oil temperature rises, the wax deposition rate increases fast, and the growth of the wax deposition rate slows down when the oil temperature is large, because when the oil temperature is higher than the wax precipitation point temperature, no wax molecules near the wall are precipitated during the period of oil temperature droping to the wax precipitation point temperature, so the deposition rate is relatively slow.

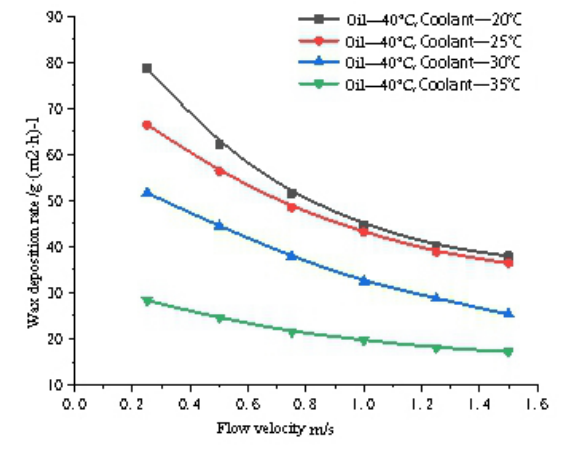

Fig. 5. Fuel oil wax deposition rate at different flow rates.

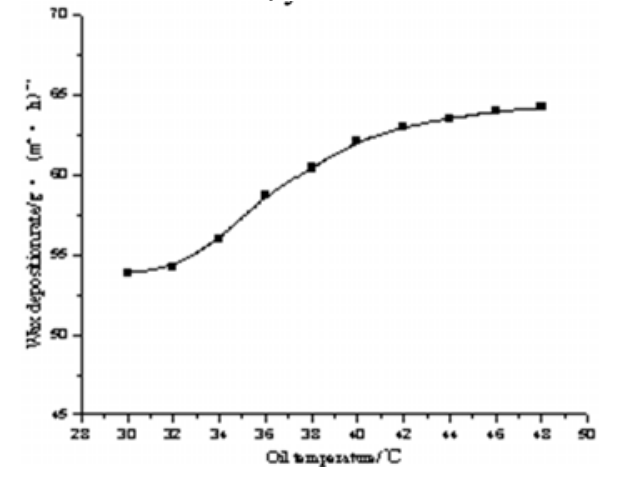

Fig. 6. Fuel oil wax deposition rate at different inlet oil temperatures.

\subsubsection{The influence of oil wall temperature difference}

As shown in Fig. $7 \mathrm{a}$, when the oil temperature is $40^{\circ} \mathrm{C}$ and the oil flow velocity is $0.5 \mathrm{~m} / \mathrm{s}$, the wax deposition rate varies with the oil wall temperature difference. When the oil flow velocity is $0.5 \mathrm{~m} / \mathrm{s}$ and the oil wall temperature difference is maintained at $10^{\circ} \mathrm{C}$, the deposition rate in different temperature ranges is shown in Fig. $7 \mathrm{~b}$. It can be found that in a temperature range where the oil temperature is higher than the freezing point temperature and lower than the wax precipitation temperature, there is a peak of wax deposition, however, the deposition rate in this interval is relatively small.

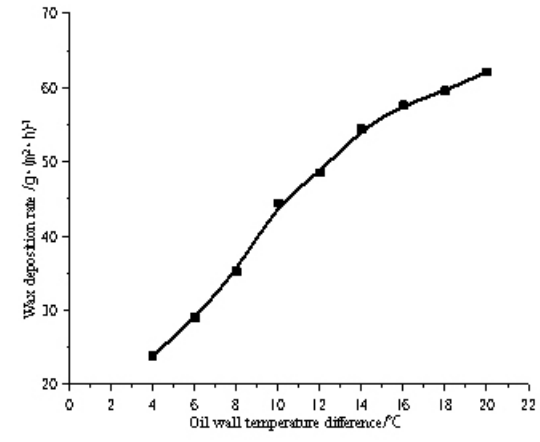

(a)Heavy oil wax deposition rate under different temperature differences of oil wall

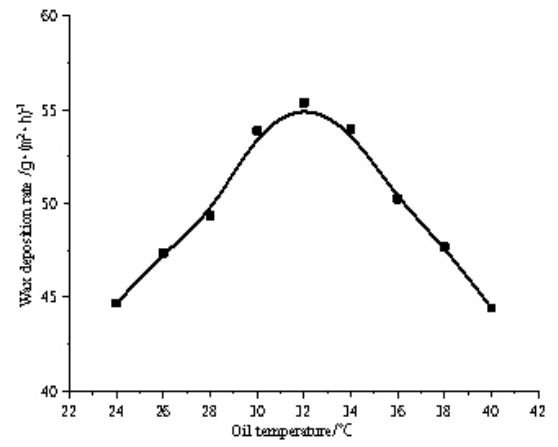

(b)Heavy oil wax deposition rate in different temperature ranges

Fig. 7. The variation of fuel oil wax deposition rate with oil wall temperature difference.

\section{Conclusion}

(1)Under the condition that the oil temperature and coolant temperature remain unchanged, 
the increase of oil flow velocity has an inhibitory effect on the wax deposition rate. Meanwhile, under the combined action of three factors, the greater the oil wall temperature difference, the faster the wax deposition rate decreases. As the oil flow rate increases, the decline of wax deposition rate gradually slows down, showing a constant trend.

(2)When the oil flow velocity and the oil wall temperature difference are constant, the wax deposition rate increases with the increase of oil temperature. When the oil temperature is low, the wax deposition rate increases faster with the increase of oil temperature. Then when the oil temperature is higher, the wax deposition rate slows down as the oil temperature increases.

(3)When the oil wall temperature difference and oil flow rate are constant, the deposition rate increases with the increase of the oil wall temperature difference. When the oil temperature is $30 \sim 34{ }^{\circ} \mathrm{C}$, it is in the wax deposition peak area, the wax deposition rate is the largest.

\section{Acknowledgments}

This project is supported by the Science and Technology Research Program of Chongqing Municipal Education Commission (Grant No. KJZD-M201912901 and KJZD-K202012903).

\section{References}

1. P. Wang, G. Y. Jiang, Y. B. Tian, et al. The effect of wax deposition thickness on oil transportation cost[J]. Journal of Petrochemical Universities, 1 (2002)

2. Takuji Kawahara. A successive approximation for turbulence in the Burgers model fluid[J]. Journal of the Physical Society of Japan, 3 (1968)

3. J. Hsu, M. M. Santamaria, J. P. Brubaker. Wax deposition of waxy live crudes under turbulent flow conditions[C]. The 69th Annual Technical Conference and Exhibition, New Orleans, LA, (1996)

4. A. Hamouda, J. Ravney. Prediction of wax deposition in pipelines and field experience on the influence of wax on drag-reducer performance[C]. The 24th Annual OTC, Houston, Texas, (1992)

5. P. Singh, R. Venkatesan, and S. Fogler. Formation and aging of incipient thin film wax-oil gels[J]. AIChE Journal, 5 (2000)

6. O. C. Hernandez, H. Hensley, C. Sarica, et al. Improvements in single-phase paraffin deposition modeling[J]. SPE Production \& Facilities, 4 (2004)

7. Haj-Shafiei S, Serafini D, Mehrotra A K . A steady-state heat-transfer model for solids deposition from waxy mixtures in a pipeline[J]. Fuel, (2014)

8. Ai Yunchao. Effect of wax deposition on safe transport of crude oil pipeline[J]. Oil and Gas Field Surface Engineering, 9 (2012)

9. Wang Fang. Aging regular research on wax deposition of the waxy crude oil pipelines[D]. Southwest Petroleum University, (2017)

10. Li Pei. The study on wax deposition of Jingxian crude oil pipeline[D]. China University of Petroleum(East China), (2014)

11. Coutinho, João A. P., Edmonds, Beryl, Moorwood, Tony. Reliable wax predictions for flow assurance[J]. Energy and Fuels, 3 (2006)

12. R. Hoffmann, L. Amundsen. Single-phase wax deposition experiments[J]. Energy \& Fuels, 2 (2010) 